\title{
Effects of different dietary ratio of physically effective neutral detergent fiber and metabolizable glucose on rumen fermentation, blood metabolites and growth performance of 8 to 10-month-old heifers
}

\author{
Jie Sun ${ }^{1}$, Jinhao $\mathrm{Xu}^{1}$, Yizhao Shen ${ }^{1}$, Mengzhi Wang ${ }^{1}$, Lihuai $\mathrm{Yu}^{1}$, and Hongrong Wang ${ }^{1, *}$
}

* Corresponding Author: Hongrong Wang Tel: +86-514-87997196, Fax: +86-514-87350440,

E-mail: hrwang@yzu.edu.cn

${ }^{1}$ College of Animal Science and Technology, Yangzhou University, Yangzhou, Jiangsu 225009, China

ORCID

Jie Sun

https://orcid.org/0000-0002-7260-7931 Jinhao Xu

https://orcid.org/0000-0001-5910-1875 Yizhao Shen

https://orcid.org/0000-0003-1678-7808 Mengzhi Wang

https://orcid.org/0000-0002-4559-3044 Lihuai Yu

https://orcid.org/0000-0001-7267-0917

Hongrong Wang

https://orcid.org/0000-0002-4980-1082

Submitted Dec 7, 2017; Revised Jan 18, 2018: Accepted Feb 8, 2018
Objective: The present study was undertaken to determine an optimal balance between the amount of physically effective neutral detergent fiber (peNDF) to metabolizable glucose (MG) on rumen fermentation, blood metabolites and growth performance of 8 to 10-month-old heifers.

Methods: A total of 15 healthy Holstein heifers weighing an average of $256 \mathrm{~kg}$ (8 month of age) were randomly assigned to three groups of five. Treatment diets consisted of the following three peNDF ${ }_{8.0} / \mathrm{MG}$ levels: 1.46 (Treatment A), 1.74 (Treatment B), and 2.08 (Treatment C). Results: The results showed that the ratio of peNDF $8.0 / \mathrm{MG}$ affected rumen fermentation, blood metabolites and growth performance of heifers. The average daily gain of heifers tended to decrease as the ratio of peNDF 8.0 MG increased $(\mathrm{p}=0.07)$. The concentrations of blood urea nitrogen, triglyceride, and cholesterol increased significantly $(\mathrm{p}<0.05)$, while the highdensity lipoprotein concentration decreased $(\mathrm{p}<0.05)$. After feeding $2 \mathrm{~h}$ and $4 \mathrm{~h}$, insulin concentration in Treatment A was greater than Treatment $C(p<0.05)$. Propionate concentration had decreasing trend $(p=0.07)$; acetate to propionate ratio and non-glucogenic to glucogenic volatile fatty acid (NGR) increased significantly $(p<0.05)$. In addition, the digestibility of dry matter, crude protein, neutral detergent fiber, and acid detergent fiber decreased significantly $(\mathrm{p}<0.05)$.

Conclusion: The present investigation indicated that dietary $\mathrm{peNDF}_{8.0} / \mathrm{MG}$ ratio can affect the growth and development, blood metabolites, rumen fermentation and apparent digestibility of heifers, and the optimal dietary $\mathrm{peNDF}_{8.0} / \mathrm{MG}$ ratio for 8 to 10 -month-old heifers in the present study was 1.46 .

Keywords: Physically Effective Neutral Detergent Fber; Metabolizable Glucose; Rumen Fermentation; Blood Metabolites; Growth Performance

\section{INTRODUCTION}

The composition of carbohydrates in diets is one of the key factors affect the growth and development of replacement heifers. It would lead to various metabolic disorders, if the carbohydrate composition in diet were imbalanced or not attaining nutrient requirement [1]. Traditionally, high-forage diets are often used in heifer herd feeding, but they are inefficiently digested due to high levels of lower digestibility forage [2]. Inefficient utilization of feeds by dairy heifers may reduce profitability. To minimize expenses during heifers rearing, high concentrate diets composed of high energy and high protein are being fed frequently to accelerate growth rates of calves and heifers. It has been demonstrated that high energy diets may affect mammary development and future milk yield potential [3]. Dietary fiber 
can affect animal metabolism, ruminal fermentation and feeding behavior. Previous studies have revealed that dietary peNDF $_{8.0}$ content had larger effects on apparent nutrient digestibility, chewing activity, eating and $18.0 \%$ dietary peNDF 8.0 content is optimal dietary for 8 to 10-month-old Holstein heifers [4]. It is necessary to quantify the physically effective neutral detergent fiber (peNDF) value in dairy cattle production. Xu et al [5] also reported that a dietary carbohydrate balance index (CBI) of 1.86 could improve the potential growth performance of heifers and promote the maintenance of healthy rumen fermentation, where the computational formula CBI $=$ peNDF/RDS, where RDS refers to ruminally degradable starch.

Nowadays, most researchers recognize the importance of glucose for ruminants [6]. To assess the adequacy of energy required by dairy cows, the concept of metabolizable glucose (MG) proposed by $\mathrm{Lu}[7,8]$ has received increasing attention because it made ruminant glucose nutrition research reach the organism metabolism level, and supplied the specific method for resolving the problems of energy metabolism and substance metabolism. The MG is defined as total amount of digestible glucose of feedstuff origin that can be provided for further use in metabolism, after digested and absorbed by ruminants. The MG in dairy cows has been intensively investigated recently. Researches such as that conducted by Song et al [9] showed that production performance and physiological indices of the Holstein cow under heat stress can be regulated by the MG in diet; it can significantly affect milk yield and feed intake of dairy cow, when the content of MG was $99.27 \mathrm{~g} / \mathrm{kg}$. MG could effectively increase the growth rate of replacement heifer and $114 \mathrm{~g} / \mathrm{kg}$ was the most suitable MG content in diet [10].

Energy efficiency and protein utilization will be improved and the organisms will maintain nitrogen balance if appropriate content of $\mathrm{MG}$ is provided. Either inadequate or excessive peNDF in the diet showed negative influence on heifers [4]. MG and peNDF are regarded as the new indexes which amalgamate information on both the apparent nutrition and the regulation of nutrient metabolism. However, limited information is available documenting the influence of interaction between peNDF and MG on heifers, and the most suitable concentration of peNDF/MG in 8 to 10-month-old dairy heifer diets is still uncertain. To find an optimal balance of $\mathrm{peNDF}_{8.0} / \mathrm{MG}$ content in the diets of dairy heifers is critical to achieve the rearing targets for nutrient utilization, optimal digestion, body size and improved productivity. The optimal $\mathrm{peNDF}_{8.0} / \mathrm{MG}$ content which we hypothesized in diets would benefit ruminal fermentation, body growth of heifers and improve feed digestion and efficiency. In this investigation, the aim was to assess the different dietary peNDF ${ }_{8.0} / \mathrm{MG}$ for growing replacement heifers and to determine the optimal dietary peNDF $_{8.0} / \mathrm{MG}$ content.

\section{MATERIALS AND METHODS}

\section{Experimental design}

Animal care and procedures were approved under established standards by the Committee of Yangzhou University on Animal Care and Ethics (No.201406118). The experiment was designed in random block design. Fifteen healthy Holstein heifer calves with similar genetic merit, initial age (7.2 \pm 0.18 months, mean \pm standard deviation [SD]) and bodyweight $(256 \pm 12.89 \mathrm{~kg}$, mean \pm SD) were randomly assigned to three treatments with five replicates. The experiment was conducted for 40-d and the heifers were given a 15-d adaptation period before exposure to the experimental treatment. The heifers were housed in individual tie stalls, and they were fed one of three diets, which were chemically identical but included different ratios of peNDF/MG, as shown in Table 1. Total mixed

Table 1. Composition, particle-size distribution and nutrient levels of the experimental diets

\begin{tabular}{|c|c|c|c|}
\hline \multirow{2}{*}{ Item } & \multicolumn{3}{|c|}{ Treatment } \\
\hline & $A(1.46)$ & $B(1.74)$ & $C(2.08)$ \\
\hline \multicolumn{4}{|l|}{ Ingredients of DM (\%) } \\
\hline Wild ryegrass hay & 32.00 & 32.00 & 32.00 \\
\hline Corn silage & 20.00 & 20.00 & 20.00 \\
\hline Corn & 30.00 & 22.00 & 15.00 \\
\hline Soybean meal & 8.00 & 8.00 & 7.00 \\
\hline Wheat bran & 3.50 & 8.00 & 13.00 \\
\hline Distiller dried grains with solubles (DDGS) & 0.00 & 7.50 & 8.50 \\
\hline Fatty acid calcium & 0.00 & 0.00 & 2.00 \\
\hline $\mathrm{CaHPO}_{4}$ & 0.50 & 0.50 & 0.50 \\
\hline $\mathrm{NaHCO}_{3}$ & 0.50 & 0.50 & 0.50 \\
\hline Limestone & 0.50 & 0.50 & 0.50 \\
\hline $\mathrm{NaCl}$ & 0.50 & 0.50 & 0.50 \\
\hline Premix ${ }^{1)}$ & 0.50 & 0.50 & 0.50 \\
\hline Corn gluten meal & 4.00 & 0.00 & 0.00 \\
\hline Total & 100.00 & 100.00 & 100.00 \\
\hline \multicolumn{4}{|l|}{ Nutrient levels } \\
\hline $\mathrm{NE}_{\mathrm{L}}(\mathrm{MJ} / \mathrm{kg})^{2)}$ & 6.65 & 6.67 & 6.70 \\
\hline Crude protein (CP) & 13.41 & 13.31 & 13.43 \\
\hline Starch & 27.31 & 25.77 & 23.25 \\
\hline Neutral detergent fiber (NDF) & 36.36 & 39.51 & 41.15 \\
\hline Acid detergent fiber (ADF) & 20.05 & 21.32 & 21.89 \\
\hline Calcium (Ca) & 0.57 & 0.58 & 0.60 \\
\hline Phosphorus (P) & 0.35 & 0.41 & 0.40 \\
\hline Metabolizable glucose (MG) & 12.41 & 11.35 & 9.88 \\
\hline \multicolumn{4}{|l|}{ DM content of matter in different sieve layer } \\
\hline $\operatorname{peNDF}_{8.0}$ & 18.18 & 19.76 & 20.58 \\
\hline peNDF $_{8.0} / \mathrm{MG}$ & 1.46 & 1.74 & 2.08 \\
\hline
\end{tabular}

1) The premix was provided with the following per $\mathrm{kg}$ of diets: Cu $10 \mathrm{mg}$, FeS$\mathrm{O}_{4} \cdot \mathrm{H}_{2} \mathrm{O} 24 \mathrm{mg}$, Zn $38 \mathrm{mg}, \mathrm{Co} 0.0024 \mathrm{mg}$, Se $0.0016 \mathrm{mg}$, Vit A 12,000 IU, Vit $D_{3}$ 10,000 IU, Vit E 25 mg, nicotinic acid 36 mg, choline 1,000 mg.

2) $\mathrm{NE}_{\mathrm{L}}$, net energy for lactation $(\mathrm{MJ} / \mathrm{kg})=0.5501 \times$ digestible energy $(\mathrm{DE} ; \mathrm{MJ} /$ $\mathrm{kg})-0.3958$.

${ }^{3)}$ The MG levels of the three diets were weighted data results, they were calculated based on the MG levels of the ingredients. 
rations were fed twice daily at $0700 \mathrm{~h}$ and $1700 \mathrm{~h}$ respectively to ensure ad libitum consumption. Water was available ad libitum to the heifers through a water bowl in each stall. The volume of feed allowed for at least a residual of $10 \%$.

\section{Feeds and diets}

The diets were formulated to meet the nutrient requirements of heifers according to NRC [11]. Treatment diets consisted of the following three levels: $\mathrm{peNDF}_{8.0} / \mathrm{MG}=1.46$ (Treatment A), $\mathrm{peNDF}_{8.0} / \mathrm{MG}=1.74$ (Treatment $\mathrm{B}$ ) and $\mathrm{peNDF}_{8.0} / \mathrm{MG}=$ 2.08 (Treatment $\mathrm{C}$ ). The composition and nutrient levels of the experimental diets are shown in Table 1 . Wild ryegrass hay was chopped into length of $7 \mathrm{~cm}$ using a chaff cutter (model 40B, Xingda Machine Com. Ltd., Zhengzhou, China). The peNDF content was measured by using a Penn State Particle Separator (Anscitech Company, Wuhan, China) [12] and the specific operation steps refer to the reference [13]. For the pef, the proportion of particles larger than $8 \mathrm{~mm}$ and less than 19 $\mathrm{mm}$ was considered to be pef ${ }_{8.0}$ as described in Lammers et al [14]. The peNDF ${ }_{8.0}$ content of the ration was calculated by multiplying the neutral detergent fiber (NDF) percentage of the mixed ration by pef $_{8.0}$. MG was calculated by the formula: $\mathrm{MG}=\mathrm{POEG}+\mathrm{BSEG}=0.09 \times \mathrm{K}_{1} \times \mathrm{Pr}+0.9 \times \mathrm{K}_{2} \times \mathrm{BS}$. Where POEG refers to the glucose that was generated from propionic acid in the rumen, BESG refers to the glucose provided by ruminant bypass starch, $\mathrm{K}_{1}$ refers to the absorptivity of propionic acid in rumen, Pr refers to the yield of propionic acid in rumen, $\mathrm{K}_{2}$ is the absorptivity of ruminal bypass starch in the intestine and BS refers to the amount of ruminal bypass starch.

Growth-performance measurements and body condition All heifers were weighed on a platform scale and withers height, body length, heart girth and abdominal girth were measured with a Biltmore stick and tape, after adaptation, at the beginning (the first day) and on the last day (the fortieth day) of the test. The heifers were driven to the fixed bar for measurements before morning feeding. Body condition score (BCS) was also evaluated on the last day of the test and the sample was rated based on a 5-point scoring scheme.

\section{Blood biochemical indexes}

A blood sample of $10 \mathrm{~mL}$ was taken from each heifer from the caudal vein before the morning feeding at the end of test (40 days); $1,300 \times g$ centrifugal with 15 min prepared serum (stored at $-20^{\circ} \mathrm{C}$ ). Serum samples were tested with automatic chemistry analyzer (SINNOW DH-364), and measuring indexes included: total serum protein (TP), albumin (ALB), glucose (GLU), urea nitrogen (UN), total cholesterol (CHOL), high-density lipoprotein (HDL) and low-density lipoprotein (LDL). Then blood samples were taken every $2 \mathrm{~h}$ for a total of six times to analyze the change of blood hormone content with measuring indexes including: insulin (INS), growth hormone $(\mathrm{GH})$, insulin-like growth factor-1 (IGF-1), prolactin (PRL).

\section{Rumen fermentation}

Rumen fluid were sampled $2 \mathrm{~h}$ after the morning feeding by an esophageal tube vacuum pump sampling device (Anscitech Company, Wuhan, China) on the three consecutive days (Days 38 to 40 ) of the experiment. Approximately $200 \mathrm{~mL}$ of rumen fluid was sampled after removing saliva from the top of the sampling bottle and then filtered through 4-layer cheesecloth to obtain the strained ruminal fluid. After collection, the ruminal $\mathrm{pH}$ was measured immediately with a hand-held electrode (model B-4, Shanghai Chemical Company, Shanghai, China) and two subsamples were preserved. To one subsample, $0.2 \mathrm{~mL}$ of $50 \%$ (vol/vol) sulfuric acid was added per $10 \mathrm{~mL}$ of rumen fluid for subsequent ammonia-nitrogen $\left(\mathrm{NH}_{3}-\mathrm{N}\right)$ analysis [15]. For the other subsample, $1 \mathrm{~mL}$ of $25 \%$ metaphosphoric acid was added per $5 \mathrm{~mL}$ of rumen fluid for volatile fatty acid analysis [16]. All samples were stored at approximately $-20^{\circ} \mathrm{C}$.

\section{Feed intake and digestibility of nutrients}

During the experimental period, feed offered and refusals were recorded before the feeding every day. The intake of each individual was calculated as the difference between the dry matter (DM) amount of offered feed and the refused. Fecal grab samples were collected 3 times daily from d 30 to 34 of the experimental period, the fecal samples were pooled by combining approximately $100 \mathrm{~g}$ of feces from each time point. Apparent nutrient digestibility was measured according to method of $4 \mathrm{~N} \mathrm{HCl}$ insoluble ash [17]. The DM content of samples was determined by drying at $135^{\circ} \mathrm{C}$ for $3 \mathrm{~h}$ [18]. Crude protein was measured with a FOSS N Analyzer (KT260, Foss Co., Hilleroed, Denmark). The NDF and acid detergent fiber (ADF) contents were sequentially analyzed by an Ankom Fiber Analyzer (Ankom Technology, Fairport, NY, USA).

\section{Statistical analysis}

All the data was built in Excel (Microsoft Office, version 2010), and all statistical analyses were performed using the SAS program (SAS Institute, Cary, NC, USA).

Using PROC MIXED of SAS, the experimental data were analyzed in a randomized trial design by using the following model: $Y_{i j k}=\mu+A_{i}+M_{j}+\varepsilon_{i j k} ; Y_{i j k}$ is the response variable, $\mu$ is the grand mean, $A_{i}$ is the random effect of the heifer ( $\left.i=1-15\right)$, $M_{j}$ is the fixed effect of diet $(j=1-3)$, and $\varepsilon_{i j k}$ is the random error, which was assumed to be normally distributed.

For all analyses, significance was established as $\mathrm{p} \leq 0.05$, and a trend was considered to exist if $0.05<p \leq 0.10$ using Duncan's new multiple range test. The values are presented as the means and standard errors. 
Table 2. Effect of different peNDF $/ 0$ MG ratios on BW, $A D G$, and DMl

\begin{tabular}{lccccc}
\hline \multirow{2}{*}{ Item } & \multicolumn{3}{c}{ Treatment } & \multirow{2}{*}{ SEM } & p-value \\
\cline { 2 - 4 } & $\mathbf{A}(\mathbf{1 . 4 6 )}$ & $\mathbf{B}(\mathbf{1 . 7 4 )}$ & $\mathbf{C}(\mathbf{2 . 0 8})$ & & \\
\hline Initial BW (kg) & 254.60 & 256.90 & 256.60 & 3.33 & 0.96 \\
Final BW (kg) & 294.20 & 294.00 & 290.80 & 3.36 & 0.91 \\
ADG (kg/d) & $0.99^{\mathrm{a}}$ & $0.93^{\mathrm{ab}}$ & $0.86^{\mathrm{b}}$ & 0.02 & 0.07 \\
DMI (kg/d) & 7.10 & 7.08 & 7.00 & 0.07 & 0.86 \\
\hline
\end{tabular}

peNDF, physically effective neutral detergent fiber; $M G$, metabolizable glucose; $B W$, body weight; $A D G$, average daily gain; DMI, dry matter intake; SEM, standard error of the mean.

1) $p$-values indicate overall diet effects.

$a, b$ In the same row, values with different small letter superscripts mean significant difference $(p<0.05)$, while with the same or no letter superscripts mean no significant difference $(p>0.05)$.

\section{RESULTS}

\section{Body growth and development}

No significant difference was found in initial body weight (BW), final BW, and average dry matter intake (Table 2). However, average daily gain $(A D G)$ tended $(\mathrm{p}<0.10)$ to decrease with the increasing ratio of $\mathrm{pNDF}_{8.0} / \mathrm{MG}$. And ADG in Treatment $\mathrm{C}$ was $0.86 \mathrm{~kg} / \mathrm{d}$, which was significantly $(\mathrm{p}<0.05)$ lower than that in Treatment A.

As shown in Table 3, different peNDF 8.0 MG levels in the diet had no obvious ( $p>0.05)$ influence on the change of withers height, body length, paunch girth and BCS. But the strength of growth from heart girth, paunch girth, body length and withers height increased successively and remarkable difference was found in heart girth $(\mathrm{p}<0.05)$.

\section{Blood biochemical indexes}

Serum biochemical parameters: No significant differences ( $\mathrm{p}>$
Table 4. Effect of different peNDF ${ }_{8.0} / M G$ ratios on serum biochemical parameters of heifers

\begin{tabular}{|c|c|c|c|c|c|}
\hline \multirow{2}{*}{ Items } & \multicolumn{3}{|c|}{ Treatment } & \multirow{2}{*}{ SEM } & \multirow{2}{*}{ p-value ${ }^{1}$} \\
\hline & $A(1.46)$ & $B(1.74)$ & $C(2.08)$ & & \\
\hline $\mathrm{TP}(\mathrm{g} / \mathrm{L})$ & 57.54 & 55.72 & 58.02 & 0.84 & 0.53 \\
\hline $\mathrm{ALB}(\mathrm{g} / \mathrm{L})$ & 38.06 & 37.28 & 37.92 & 0.24 & 0.39 \\
\hline Crea ( $\mu \mathrm{mmol} / \mathrm{L})$ & 182.84 & 182.06 & 187.02 & 2.99 & 0.79 \\
\hline Glu (mmol/L) & 5.57 & 5.59 & 5.35 & 0.07 & 0.27 \\
\hline FFA (ng/mL) & 610.15 & 551.55 & 600.29 & 14.57 & 0.47 \\
\hline $\mathrm{HDL}(\mathrm{mmol} / \mathrm{L})$ & $3.34^{\mathrm{a}}$ & $2.66^{\mathrm{ab}}$ & $2.44^{b}$ & 0.16 & 0.04 \\
\hline LDL (mmol/L) & 1.39 & 1.16 & 1.04 & 0.89 & 0.27 \\
\hline $\mathrm{TG}(\mathrm{mmol} / \mathrm{L})$ & $0.33^{b}$ & $0.32^{b}$ & $0.43^{\mathrm{a}}$ & 0.02 & 0.04 \\
\hline $\mathrm{CHOL}(\mathrm{mmol} / \mathrm{L})$ & $2.57^{b}$ & $2.64^{\mathrm{ab}}$ & $3.16^{\mathrm{a}}$ & 0.11 & 0.05 \\
\hline UN (mmol/L) & $3.83^{b}$ & $4.36^{\mathrm{ab}}$ & $4.82^{\mathrm{a}}$ & 0.16 & 0.03 \\
\hline
\end{tabular}

peNDF, physically effective neutral detergent fiber; $M G$, metabolizable glucose; SEM, standard error of the mean; TP, total serum protein; ALB, albumin; FFA, free fatty acid; HDL, high-density lipoprotein; $L D L$, low-density lipoprotein; $T G$, triglyceride; CHOL, cholesterol; UN, urea nitrogen.

1) $p$-values indicate overall diet effects.

$a, b$ In the same row, values with different small letter superscripts mean significant difference $(p<0.05)$, while with the same or no letter superscripts mean no significant difference $(p>0.05)$.

0.05) were observed in TP, ALB, Crea, Glu, free fatty acid (FFA) and LDL among all groups (Table 4). Another important finding was that the concentration of triglyceride (TG), $\mathrm{CHOL}$ and blood urea nitrogen (BUN) improved with the increasing $\mathrm{peNDF}_{8.0} / \mathrm{MG}$ ratio. By contrast, the HDL showed a downward trend with the increasing peNDF 8.0 MG ratio; The HDL in Treatment A were much higher than those in the other two treatments $(p<0.05)$, but the difference of HDL in Treatment $A$ and $B$ was not obvious ( $\mathrm{p}>0.05)$.

Serum hormones: From Figure 1, it is observed that the mean of INS, IGF-1, GH, and PRL offered a descending ten-

Table 3. Effect of different peNDF 8 8.0 MG ratios on the body size and body condition score of heifers

\begin{tabular}{|c|c|c|c|c|c|}
\hline \multirow{2}{*}{ Items } & \multicolumn{3}{|c|}{ Treatment } & \multirow{2}{*}{ SEM } & \multirow{2}{*}{$p$-value ${ }^{1)}$} \\
\hline & $A(1.46)$ & $\mathrm{B}(1.74)$ & $C(2.08)$ & & \\
\hline Withers height, initial (cm) & 111.40 & 113.02 & 112.00 & 0.52 & 0.47 \\
\hline Change $(\mathrm{cm} / \mathrm{d})$ & 0.09 & 0.08 & 0.09 & 0.03 & 0.89 \\
\hline Body length, initial (cm) & 127.80 & 129.00 & 127.60 & 0.65 & 0.67 \\
\hline Final $(\mathrm{cm})$ & 136.40 & 136.40 & 136.20 & 0.88 & 1.00 \\
\hline Heart girth, initial (cm) & 149.60 & 146.80 & 146.80 & 0.67 & 0.15 \\
\hline Final $(\mathrm{cm})$ & 154.80 & 155.80 & 155.80 & 0.82 & 0.87 \\
\hline Change $(\mathrm{cm} / \mathrm{d})$ & $0.13^{b}$ & $0.22^{\mathrm{a}}$ & $0.22^{\mathrm{a}}$ & 0.06 & 0.01 \\
\hline Paunch girth, initial (cm) & 180.20 & 177.00 & 179.40 & 0.97 & 0.40 \\
\hline Final $(\mathrm{cm})$ & 189.60 & 187.40 & 190.10 & 1.00 & 0.54 \\
\hline
\end{tabular}

peNDF, physically effective neutral detergent fiber; MG, metabolizable glucose; SEM, standard error of the mean.

1) $p$-values indicate overall diet effects.

${ }_{a, b}$ In the same row, values with different small letter superscripts mean significant difference $(p<0.05)$, while with the same or no letter superscripts mean no significant difference $(p>0.05)$. 
(a) IGF-1

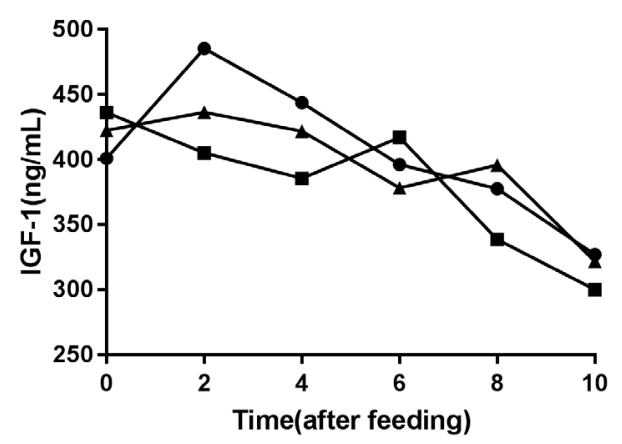

(c) PRL

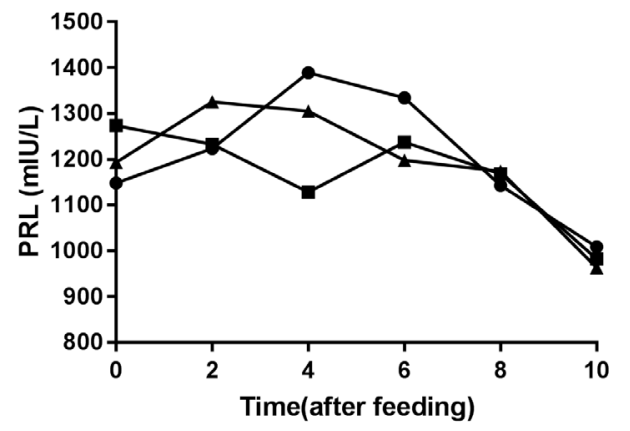

(b) $\mathrm{GH}$

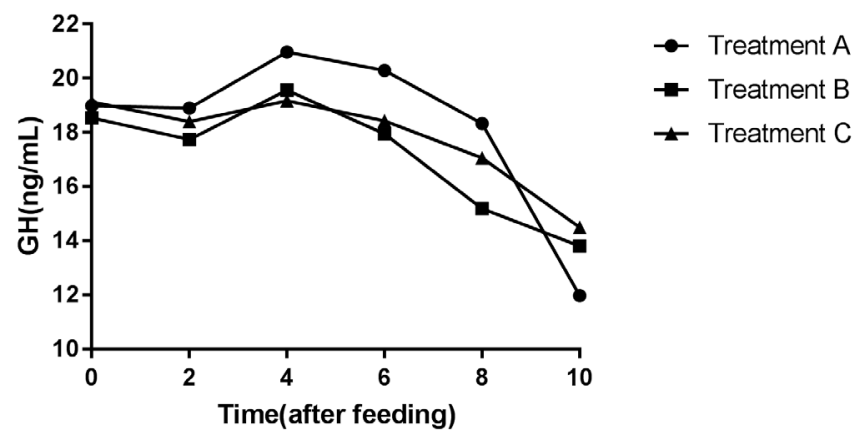

(d) INS

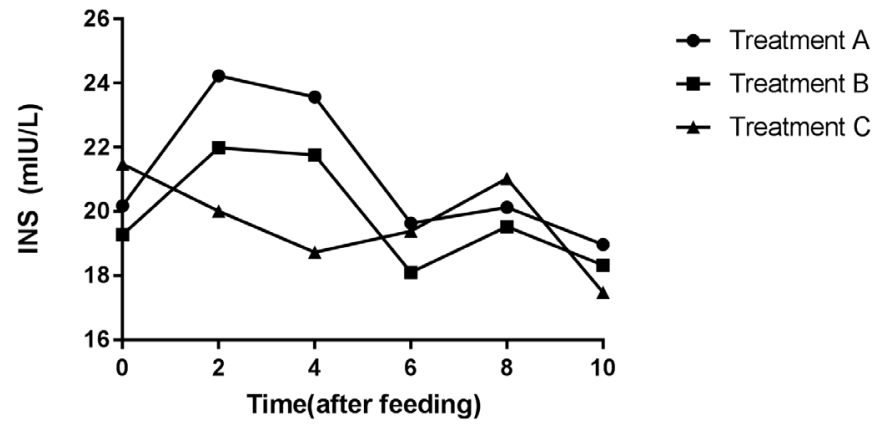

Figure 1. Effect of different peNDF $F_{8.0} / M G$ ratios on serum hormone at different time points of feeding heifers. (a) IGF-1, $p=0.27 ;$ (b) GH, $p=0.36$; (c) PRL, $p=0.85$; (d) INS, $p=0.36$. p-values indicate overall diet effects. peNDF, physically effective neutral detergent fiber; MG, metabolizable glucose; IGF-1, insulin-like growth factor-1; PRL, prolactin; INS, insulin.

dency from 0 to $10 \mathrm{~h}$ after feeding, and the four hormones at different time points unfold a characteristic of pulsed fluctuations. Those values were highest in Treatment $\mathrm{A}$. At the time point $2 \mathrm{~h}$ and $4 \mathrm{~h}$, the mean of serum INS concentration in Group A were greater higher $(\mathrm{p}<0.05)$ than those in Group C. Meanwhile, it can be found that mean concentration of INS, PRL, IGF-1, and GH were tending towards stability at $0,6,8$, and $10 \mathrm{~h}$ among three treatments. Compared with Treatment $\mathrm{C}$, there was an obvious declining trend of BUN in Treatment $\mathrm{A}(\mathrm{p}<0.05)$. In addition, a difference was not noted among the various treatments by statistically analyzing.

\section{Rumen $\mathrm{pH}$ and fermentation}

As shown in Table 5, the $\mathrm{pH}$ value was not significantly ( $\mathrm{p}>$ 0.05 ) enhanced by increasing peNDF/MG ratios, and the ruminal $\mathrm{pH}$ levels were above 6.5 in all treatments. The results showed that $\mathrm{NH}_{3}-\mathrm{N}$ concentration in Treatment A was substantially below in Treatment C. Moreover, no significant ( $\mathrm{p}>$ 0.05 ) effect of the treatments was observed on the total VFA concentration, and the percentages of acetic acid, butyric acids and branched-chain fatty acids remained unchanged among the treatments. The proportion of propionate acid was significantly decreased by an increasing peNDF ${ }_{8.0} / \mathrm{MG}$ ratio, and the highest value of propionate was obviously in Treatment $\mathrm{A}(\mathrm{p}<$ $0.05)$, as well as acetate to propionate ratio $(\mathrm{A} / \mathrm{P})$ and non- glucogenic to glucogenic volatile fatty acid (NGR).

\section{Nutrient digestibility}

Digestibility of DM, crude protein (CP), ADF, and NDF

Table 5. Effect of different peNDF/MG ratios on characteristics of rumen fermentation of heifers

\begin{tabular}{lccccc}
\hline \multirow{2}{*}{ Items } & \multicolumn{3}{c}{ Treatment } & \multirow{2}{*}{ SEM } & p-value ${ }^{\text {1) }}$ \\
\cline { 2 - 4 } & $\mathbf{A}(\mathbf{1 . 4 6})$ & $\mathbf{B}(\mathbf{1 . 7 4 )}$ & $\mathbf{C}(\mathbf{2 . 0 8 )}$ & & \\
\hline $\mathrm{pH}$ & 6.51 & 6.53 & 6.66 & 0.05 & 0.48 \\
$\mathrm{NH}_{3}$-N (mg/100 mL) & $14.25^{\mathrm{a}}$ & $11.76^{\mathrm{ab}}$ & $8.88^{\mathrm{b}}$ & 0.78 & 0.01 \\
Total VFA (mmol/L) & 85.50 & 71.84 & 78.79 & 3.26 & 0.25 \\
Acetate (\%) & 68.75 & 69.56 & 69.34 & 0.27 & 0.49 \\
Propionate (\%) & $18.59^{\mathrm{a}}$ & $17.58^{\mathrm{b}}$ & $17.74^{\mathrm{b}}$ & 0.20 & 0.07 \\
Butyrate (\%) & 9.13 & 9.65 & 9.74 & 0.18 & 0.36 \\
BCFA $^{2)}(\%)$ & 2.59 & 2.41 & 2.32 & 0.08 & 0.40 \\
Acetic/propionate $^{2}$ & $3.70^{\mathrm{b}}$ & $3.97^{\mathrm{a}}$ & $3.91^{\mathrm{a}}$ & 0.06 & 0.04 \\
NGR $^{3)}$ & $4.50^{\mathrm{b}}$ & $4.89^{\mathrm{a}}$ & $4.82^{\mathrm{a}}$ & 0.07 & 0.03 \\
\hline
\end{tabular}

peNDF, physically effective neutral detergent fiber; $M G$, metabolizable glucose; SEM, standard error of the mean; VFA, volatile fatty acid.

1) $p$-values indicate overall diet effects.

2) BCFA is branched-chain fatty acids (isovaleric acid and isobutyric acid).

${ }^{3)}$ NGR is the ratio of non-glucogenic fatty acid to glucogenic fatty acid, the method for its calulation is NGR = (acetate $+2 \times$ butyrate+valeric)/(propionate+valeric).

${ }^{a, b}$ In the same row, values with different small letter superscripts mean significant difference $(p<0.05)$, while with the same or no letter superscripts mean no significant difference $(p>0.05)$. 
Table 6. Effect of different peNDF $8.0 / M G$ ratios on nutrient digestibility of heifers $(\%)$

\begin{tabular}{lccccc}
\hline \multirow{2}{*}{ Items } & \multicolumn{3}{c}{ Treatment } & SEM & p-value ${ }^{1)}$ \\
\cline { 2 - 4 } & $\mathbf{A}(\mathbf{1 . 4 6})$ & $\mathbf{B}(\mathbf{1 . 7 4})$ & $\mathbf{C}(\mathbf{2 . 0 8 )}$ & & \\
\hline DM & $75.57^{\mathrm{a}}$ & $63.63^{\mathrm{b}}$ & $58.11^{\mathrm{c}}$ & 3.05 & $<0.01$ \\
CP & $78.32^{\mathrm{a}}$ & $72.66^{\mathrm{b}}$ & $63.40^{\mathrm{c}}$ & 2.51 & $<0.01$ \\
NDF & $65.82^{\mathrm{a}}$ & $57.87^{\mathrm{b}}$ & $57.52^{\mathrm{b}}$ & 3.44 & 0.01 \\
ADF & $60.32^{\mathrm{a}}$ & $50.46^{\mathrm{b}}$ & $51.00^{\mathrm{b}}$ & 3.42 & 0.01 \\
\hline
\end{tabular}

peNDF, physically effective neutral detergent fiber; $\mathrm{MG}$, metabolizable glucose; SEM, standard error of the mean; DM, dry matter; CP, crude protein; NDF, neutral detergent fiber; $A D F$, acid detergent fiber.

${ }^{1)} p$-values indicate overall diet effects.

$a, b, c$ In the same row, values with different small letter superscripts mean significant difference $(p<0.05)$, while with the same or no letter superscripts mean no significant difference $(p>0.05)$.

decreased $(\mathrm{p}<0.05)$ with increasing $\mathrm{peNDF}_{8.0} / \mathrm{MG}$ as demonstrated in Table 6. A significant difference was observed in the apparent digestibility of DM and $\mathrm{CP}(\mathrm{p}<0.05)$. The highest apparent digestibility of DM and CP was observed in Treatment A ( $\mathrm{p}<0.05)$, and so were nutrient digestibility of NDF and ADF.

\section{DISCUSSION}

Dairy heifer growth, body size and ADG at the first calving can affect future milk yield potential, they are regarded as an important management target for the future of heifers [19]. Fiber content and energy level of the diet are two important factors which we should take into consideration during the process of dairy cows production. It has been demonstrated that the peNDF content in diets had no significant effect on BW, DG, and DMI of heifer herds [4]. In addition, some studies showed that the MG level in the diet had no significant effect on the BW and DMI, but it may promote the daily gain of heifer herds [10]. The present study obtained similar results and there was a tendency to decrease the ADG of the test herds. The reason for decreasing ADG might be explained based on the fact that different MG resulted in different energy intake. It was also found in Ge's [20] research that the ADG improved dramatically with increasing MG content. In this study, heifers had best growth performance when peNDF ${ }_{8.0} / \mathrm{MG}$ ratio in the diet was 1.46 , and we predict that the weight of the heifers would be ranged from $380 \mathrm{~kg}$ to 400 $\mathrm{kg}$ at the age of 13 months according to the tendency.

Cows with smaller udders and greater abdominal circumference had higher lactation rates [21]. We found lower $\mathrm{peNDF}_{8.0} / \mathrm{MG}$ ratio in diet can significantly reduce udder development, which was beneficial to milk production. In this study, the BCS of heifers ranged from 2.7 to 2.8 , which was consistent with the recommendations [22]. It also implied that the heifers were in good condition. The content levels of HDL, LDL, CHOL, and TG reflected the absorption, metabolism and utilization of lipids; the lower the TG content, the higher utilization of fat. The TG content in Treatment A was low. It illustrated that lower peNDF $\mathrm{F}_{8 .} / \mathrm{MG}$ ratio is conducive to decrease serum level of lipids, and overweight could also be avoided. The main physiological functions of HDL is to transport CHOL to cells throughout the body, and finally to the liver for bile acid synthesis [23]; LDL enriched CHOL will lead to atherosclerosis if the content is too high [24]. The results of this experiment showed that the concentration of HDL and $\mathrm{CHOL}$ had inverse relation in the same treatment, which indicated that lower peNDF$_{8.0} / \mathrm{MG}$ ratio could promote $\mathrm{CHOL}$ metabolism and reduce $\mathrm{CHOL}$ deposition in the body thereby improving the content of HDL. FFA has been identified as one of major contributing factors for energy balance of the body [25]. When the energy cannot meet metabolic need, the result will be elevated FFA in blood [26]. During the experiment, the results showed that FFA was not affected by peNDF$_{8.0} / \mathrm{MG}$ ratio in the diet; this is probably a result of the same energy level being provided. It has been demonstrated that elevated serum BUN level results in strengthening protein decomposition; but there will be an increased protein synthesis and improved utilization of nitrogen, if protein decomposition has declining trend. In this experiment, the declining trend of BUN indicated that lower peNDF ${ }_{8.0} / \mathrm{MG}$ ratio (Treatment A) may promote the utilization of nitrogen and deposition of protein synthesis.

The growth of animals is regulated by hormones and growth factors. INS plays an important role in promoting the storage of glycogen TG, reducing the glucose content and facilitating protein synthesis. Data from previously published papers have identified a significant positive correlation between INS content and serum glucose level in pregnant sheep [27]. The level of INS significantly increased in Treatment $\mathrm{A}$ at 2 and $4 \mathrm{~h}$ after feeding; because high MG diet contributed to the elevated level of glucose, then endocrine cells produced more INS to regulate hormone balance in the body. Radcliff [28] reported that giving exogenous $\mathrm{GH}$ to heifer herds increased $\mathrm{ADG}$, it also can prompt feed conversion rate and reduced body fat deposition rate. GH exerts some of its action via IGF-1, and consistent with this, the concentration of IGF-1 in blood is increased by GH treatment [29]. The current study found that the concentration of GH and IGF-1 were highest in Treatment A for a period of time after feeding, and the concentration of IGF- 1 tended to increase at $2 \mathrm{~h}$ in Treatment A. The change of ADG was also consistent with the above results. PRL is a hormone secreted by the pituitary gland, which can promote growth, development and lactation. The results showed that the level of PRL in Group A was significantly higher than that in the Group B at $4 \mathrm{~h}$ after feeding, but there were no difference at the rest of the time points. It's probably affected by different diets treatment, but the relationship of the two factors needs further research. 
Ruminal $\mathrm{pH}$ is a fundamental index used to evaluate rumen fermentation conditions. It reflects the balance between organic acid production in the rumen and acid removal through neutralization and absorption within the rumen [4]. The rumen microbe growth depends on carbohydrates supply in diet; it will also contribute to the occurrence of rumen acidosis, if ruminants are given too much fermentable carbohydrates [30]. In this study, the ruminal $\mathrm{pH}$ in heifers ranged from 6.5 to 6.7 , which was far from the range of 5.2 to 5.6 (SARA). It indicated that the diets we provided had an appropriate ratio of $\mathrm{peNDF}_{8.0} /$ MG content and there was a dynamic balance between rumen microorganisms, host and also between microbes. Rumen $\mathrm{NH}_{3}-\mathrm{N}$ is the degradation product of protein and non-protein $N$. And it is used for bacterial protein synthesis. The $\mathrm{NH}_{3}-\mathrm{N}$ concentration in Treatment A was much higher than that in Treatment $\mathrm{C}$, although the $\mathrm{CP}$ content in three treatments was the same. The reason for decreasing $\mathrm{NH}_{3}-\mathrm{N}$ concentration could be explained based on the fact that microbes quickly multiply and the $\mathrm{NH}_{3}-\mathrm{N}$ was used to synthesize the microbe protein.

Ruminal VFA reflects an integrated balance of organic acid that could be affected by the production, absorption, and turnover rate in the rumen [4]. Previous studies have revealed that the concentration of total VFA is closely correlated with the combined effect of coarse fodder and MG, but the single factor of MG has no effect on total VFA [31]. The current study obtained similar results that the total VFA had no obvious change with the decreasing MG level. Acetate acid would be produced by fiber degradation in rumen, whereas starch degradation produces more propionic acid. Firkins et al [32] observed that the acetate to propionate ratio correlated positively with forage NDF and negatively with nonstructural carbohydrates in the diet of dairy cows. Data from current study illustrates that the differences of molar ratio between acetic acid and butyric acid in rumen fluid among each treatments were not significant. The NDF content in Treatment A was low, but there was a high digestion rate of NDF. The molar ratio of propionate manifested a decreasing tendency with increasing peNDF $\mathrm{F}_{80} / \mathrm{MG}$, that was because starch content in the diet was gradually increasing from Group $\mathrm{C}$ to Group A. A/P and NGR are two important indicators, which may decide the rumen fermentation pattern [7]. In this experiment, $\mathrm{A} / \mathrm{P}$ and NGR increased remarkably when peNDF $\mathrm{F}_{8.0} / \mathrm{MG}$ was raised. It confirmed that the ratio of dietary $\mathrm{peNDF}_{8.0} / \mathrm{MG}$ could have a significant effect on the rumen fermentation pattern.

To a large extent, nutrient digestibility would be influenced by the ability of ruminal degradation. Several studies have revealed that the dietary peNDF content made a significant impact on replacement heifers' nutrient digestibility [4], while the MG content was without influence on the apparent digestibility $[10,20]$. Heifers were fed the diet with the same peNDF ${ }_{8.0}$, however, we found that the apparent digestibility changed which were inconsistent with previous studies. This could be due to the content of glucose supplied to the body was reduced, the lower MG content, the less glucose supplied and digestive juices secreted. The activity of rumen microbes could also be influenced accordingly.

\section{CONCLUSION}

During the experiment with dairy heifers, carbohydrate composition was expressed as the ratio peNDF to MG. We recommended a dietary peNDF/MG of 1.46 to promote the maintenance of healthy rumen fermentation and to improve the potential growth performance of 8 to 10 months old heifers. This finding will enhance current knowledge and help establish additional alternative dietary recommendations for dairy replacement heifers.

\section{CONFLICT OF INTEREST}

We certify that there is no conflict of interest with any financial organization regarding the material discussed in the manuscript.

\section{ACKNOWLEDGMENTS}

The authors would like to acknowledge the funding received to conduct this study from the project funded by the Top Talent Award Plan of Yangzhou University (2016), the National Science and Technology Support Program (12th Five-Year Plan), the Ministry of Science and Technology of China (Grant No. 2012BAD12B02-2) and the Priority Academic Program Development of Jiangsu Higher Education Institutions (PAPD). The authors would like to express their gratitude to the staffs at the Yangzhou University Experimental Farm for providing dairy heifers for this experiment. We also grateful to our colleagues, Ms Beibei Jiang, Mr. Rufang Ge, Ms Huihui Cui, $\mathrm{Mr}$ Yu Pi and Mr Jian Gao at ruminant laboratory of YZU for their assistance with sampling and data analysis.

\section{REFERENCES}

1. Feng YL. Ruminant nutrition. Beijing, China: Science Press; 2004.

2. Zanton GI, Heinrichs AJ. The effects of controlled feeding of a high-forage or high- concentrate ration on heifer growth and first-lactation milk production. J Dairy Sci 2007;90:3388-96.

3. Brown EG, VandeHaar MJ, Daniels KM, et al. Effect of increasing energy and protein intake on mammary development in heifer calves. J Dairy Sci 2005;88:595-603.

4. Wang HR, Chen Q, Chen LM, et al. Effects of dietary physically effective neutral detergent fiber content on the feeding behav- 
ior, digestibility, and growth of 8- to 10-month-old Holstein replacement heifers. J Dairy Sci 2017;100:1161-9.

5. Xu JH, Wang HR, Shen YZ, et al. Impact of dietary carbohydrate balance on rumen fermentation, eating behaviour, growth and development of 8-10-month-old heifers. Anim Prod Sci 2017 May 29 [Epub]. https://doi.org/10.1071/AN16118

6. Allen MS, Knowlton KF. Non-structural carbohydrates important for ruminants. Feedsruffs 1995;69:13-5.

7. Lu DX. Theoretical system of glucose nutrition manipulation for ruminants and its application in feeding practice. Anim Husb Feed Sci 2010;31:402-9. [in Chinese, English abstract].

8. Lu DX. Systems nutrition: an innovation of a scientific system in animal nutrition. Front Biosci 2014;E6:55-61.

9. Song LR, Xue B, Yan FQ, Yan TH, Xiao J. Dietary metabolizable glucose level affects performance and physiological indices of dairy cows under heat stress. Chinese J Anim Nutr 2014;26:1477-85. [in Chinese, English abstract].

10. Fu C, Wang HR, Wang MZ, Yu LH, Huo YJ. Effects of different dietary metabolizable glucose levels on growth and development, nutrients digestibility and serum biochemical indices of 8 to 10-month-old heifers. Chinese J Anim Nutr 2014;26: 2615-22. [in Chinese, English abstract].

11. NRC (National Research Council). Nutrient requirements of dairy cattle. Washington, DC, USA: National Academy Press; 2001.

12. Kononoff PJ, Heinrichs AJ, Buckmaster DR. Modification of Penn State forage and total mixed ration particle separator and the effects of moisture content on its measurements. J Dairy Sci 2003;86:1858-63.

13. Heinrichs J, Kononoff P. Evaluating particle size of forages and TMRs using the Penn State particle size separator. State College, PA, USA: University Park, PA; 1996.

14. Lammers BP, Buckmaster DR, Heinrichs AJ. A simple method for the analysis of particle sizes of forage and total mixed rations. J Dairy Sci 1996;79:922-8.

15. Broderick GA, Kang JH. Automated simultaneous determination of ammonia and total amino acids in ruminal fluid and in vitro media. J Dairy Sci 1980;63:64-75.

16. Yue Q, Yang HJ, Cao YC, et al. Feruloyl and acetyl esterase production of an anaerobic rumen fungus Neocallimastix sp. YQ2 effected by glucose and soluble nitrogen supplementations and its potential in the hydrolysis of fibrous feedstuffs. Anim Feed Sci Technol 2009;153:263-77.

17. Lee C, Hristov AN. Evaluation of acid-insoluble ash and indigestible neutral detergent fiber as total-tract digestibility markers in dairy cows fed corn silage-based diets. J Dairy Sci 2013; 96:5295-9.

18. AOAC. Official methods of analysis. 15th ed. Assoc. Off. Anal. Chem., Arlington, VA, USA: AOAC International; 1990.

19. Lascano GJ, Zanton GI, Suarez-Mena FX, Heinrichs AJ. Effect of limit feeding high- and low-concentrate diets with Saccharomyces cerevisiae on digestibility and on dairy heifer growth and first-lactation performance. J Dairy Sci 2009;92:5100-10.

20. Ge RF. Study on the requirement of dietary metabolizable glucose and metabolizable protein for 8 to 10-month-old holstein heifers [master 's thesis]. Yangzhou, China: Yangzhou University; 2016.

21. Sieber M, Freeman AE, Kelley DH. Relationships between body measurements, body weight, and productivity in Holstein dairy cows. J Dairy Sci 1988;71:3437-45.

22. Dong DK. Dairy cow body condition score. J Dairy Sci Technol 2000;93:28-32 [in Chinese, English abstract].

23. Cong YY, Zhao WH. Determination the density of alfalfa flavonoid by UV spectrophotometric. Li Shi Zhen Med Res 2006;17:363 [in Chinese].

24. Dombos DL, Spencer GF, Miller RW. Medicarpin delays alfalfa seed germination and seedling growth. Crop Sci 1990;30:1626.

25. Schulz K, Frahm J, Kersten S, et al. Effects of elevated parameters of subclinical ketosis on the immune system of dairy cows: in vivo and in vitro results. Arch Anim Nutr 2015;69:113-27.

26. Mann S, Yepes FAL, Overton TR, et al. Dry period plane of energy: Effects on feed intake, energy balance, milk production, and composition in transition dairy cows. J Dairy Sci 2015; 98:3366-82.

27. Leng J, Wang G, Zhu RJ, et al. The effects of different supplementary feeding levels on blood hormones and biochemical indexes in different pregnant stages of nubian ewes. Chinese Anim Husb Vet 2011;38:21-4 [in Chinese, English abstract].

28. Radcliff RP, Vandehaar MJ, Chapin LT, et al. Effects of diet and injection of bovine somatotropin on prepubertal growth and first-lactation milk yields of Holstein cows. J Dairy Sci 2000;83: 23-9.

29. Breier BH, Gluckman PD, Bass JJ. Influence of nutritional status and oestradiol-17b on plasma growth hormone, insulinlike growth factors-Iand IIand the response to exogenous growth hormone in young steers. J Endocrinol 1988;118:24350.

30. Li S, Khafipour E, Krause DO, et al. Effects of subacute ruminal acidosis challenges on fermentation and endotoxins in the rumen and hindgut of dairy cows. J Dairy Sci 2012;95:294303.

31. Zhao R. Effects of dietary different roughage and metabolizable glucose content on digestion metabolism and productive performances of Hu lambs [master 's thesis]. Yangzhou, China: Yangzhou University; 2016.

32. Firkins JL, Eastridge ML, St-Pierre NR, Noftsger SM. Effects of grain variability and processing on starch utilization by lactating dairy cattle. J Anim Sci 2001;79:218-38. 